\title{
O ICMS ECOLÓGICO COMO FORMA DE PAGAMENTO POR SERVIÇOS AMBIENTAIS AOS MUNICÍPIOS PARAENSES PARA A REDUÇÃO DO DESMATAMENTO AMAZÔNICO
}

\author{
THE ECOLOGICAL VAT AS A KIND OF PAYMENT FOR \\ ENVIRONMENTAL SERVICES TO MUNICIPALITIES OF PARA STATE IN \\ ORDER TO REDUCE AMAZONIAN DEFORESTATION
}

\author{
Luciano Ferreira* \\ Lise Tupiassu**
}

\begin{abstract}
Resumo: O presente artigo trata da qualificação do ICMS Ecológico instituído no Estado do Pará como uma modalidade de pagamento por serviços ambientais, uma vez que a repartição das receitas do ICMS aos municípios pelo critério ecológico atende a necessidade de concessão de um estímulo econômico ao sujeito - município - para que proteja a floresta amazônica (bem da natureza gerador de serviços ecossistêmicos) das consequências do desmatamento ilegal. $\mathrm{O}$ artigo funda-se inicialmente em elementos doutrinários sobre a valorização dos serviços ecossistêmicos fornecidos pelos espaços florestais para, a partir da análise da evolução do desmatamento amazônico, e dos critérios para os repasses de ICMS realizados aos municípios paraenses verificar a importância do incentivo financeiro fornecido pelo ICMS em contrapartida com os valores de exploração econômica das áreas amazônicas ilegalmente desmatadas.
\end{abstract}

Palavras-chave: Amazônia; ICMS ecológico; Serviços ambientais; Redução do desmatamento; Tributação ambiental.

\begin{abstract}
This article deals with the qualification of the Ecological VAT introduced in Para State as a kind of payment for environmental services, since the VAT revenue transferred to municipalities by ecological criteria meets the need for granting of an economic stimulus to the protection of the Amazon forest from deforestation. The article is initially based on doctrinal elements about the valuation of ecosystem services provided by forests. Then, from the analysis of the evolution of Amazonian deforestation, and the ecological criteria for the VAT transfers to Pará municipalities, we verify the importance of the given financial incentive to compensate the economic exploitation values of Amazonian illegally deforested areas.
\end{abstract}

Key-words: Amazonia; Ecological VAT; Ecosystem Services; Environmental taxation; Reducing deforestation.

\footnotetext{
* Mestrando em Direito, Políticas Públicas e Desenvolvimento Regional no Centro Universitário do Estado do Pará. E-mail: lucianocsferreira@gmail.com.

** Doutora em direito público pela Université Toulouse 1. Mestre em direito tributário pela Université Paris 1 - Panthéon/Sorbonne e em instituições jurídico-políticas pela Universidade Federal do Pará. Professora da Universidade Federal do Pará e do Centro Universitário do Estado do Pará. Procuradora Federal. E-mail: ltupiassu@gmail.com.
} 


\section{INTRODUÇÃO}

Gonzalo Enrique Vásquez Enríquez, em sua tese de doutorado (ENRÍQUEZ, 2008), relata que, no ano 2000, enquanto a República Dominicana possuía cobertura florestal em $28 \%$ de seu território, o Haiti contava apenas com $1 \%$ de seu território com florestas.

Essa falta considerável de manta florestal gerou ao Haiti problemas que vão desde a falta de materiais (madeira) de construção, passando pela erosão e perda de fertilidade do solo, até a perda da proteção das bacias hidrográficas, tendo como consequência a redução do potencial de geração de energia hidrelétrica.

Apesar de todas essas consequências, Gonzalo Enríquez aponta que o mais grave dos problemas foi a falta de madeira para fazer carvão, que é o principal combustível para a cozinha dos haitianos, ou seja, a inexistência de florestas afetou inclusive os hábitos alimentais do local (ENRÍQUEZ, 2008).

A partir do ocorrido no Haiti, percebe-se com facilidade a importância da existência de florestas para a vida do ser humano e, por consequência, a necessidade de protegê-las.

As florestas funcionam como instrumento de bem-estar ao homem, fornecendo-lhe serviços ecossistêmicos relacionados à preservação da sobrevivência e da subsistência da espécie humana.

Desse modo, são necessários encontrar ações práticas e coerentes para o uso sustentável das florestas, sobretudo a da floresta amazônica, evitando a atuação de "garimpeiros", que saqueiam das florestas suas madeiras nobres, palmitos, orquídeas e depois ateiam fogo no restante (VIANA, 2007, p. 28).

Protegê-las do desmatamento irregular e descontrolado, mudando o ideário de que o "mato" é sinônimo de atraso e de que o progresso só existe em pastos e plantações, é tarefa que compete ao Estado e à sociedade. O Estado por meio de políticas de comando e controle ou mercado atua sobre os interesses dos particulares e, por vezes, de seus próprios interesses.

Ou determina obrigações a serem cumpridas, ou concede incentivos, econômicos ou tributários, para que determinadas finalidades do uso sustentável das florestas seja alcançado. Ou, ainda, implementa ambas as medidas em conjunto, visando maior efetividade a seus objetivos. 
O ICMS ecológico como forma de pagamento por serviços ambientais aos municípios paraenses para a redução do desmatamento amazônico

Nesse artigo, pretende-se demonstrar que a política pública denominada ICMS Ecológico estabelecida no Estado do Pará representa uma política de mercado escolhida pelo Estado para incentivar os municípios à manutenção dos serviços ecossistêmicos da floresta amazônica, o que lhe enquadrada como uma forma de pagamento por serviços ambientais (PSA).

Inicialmente, apresenta-se a importância dos serviços ecossistêmicos das florestas, para, em seguida, demonstrar que seu uso econômico descontrolado têm causado a redução dos benefícios ecossistêmicos. Em razão desse quadro traçado, posteriormente reconhece-se a existência de um dever jurídico constitucional de proteção da integridade dos serviços ambientais florestais, que pode se desenvolver por meio de políticas de comando e controle ou de mercado, como pelo pagamento pelos serviços ecossistêmicos. Por fim, diante do quadro do desmatamento na Amazônia, apresenta-se a política pública do ICMS Ecológico, instituída no Estado do Pará, como uma forma de pagaento pelos serviços ambientais.

\section{SERVIÇOS ECOSSISTÊMICOS DAS FLORESTAS}

As florestas são bens da natureza fundamentais à sustentabilidade ${ }^{1}$, tendo importante função de interação e equilíbrio entre as esferas bioquímicas de nosso planeta (atmosfera, hidrosfera, litosfera e criosfera), pois "preservam os solos, regulam os regimes hidrológicos, os ciclos de nutrientes e de trocas de gases na atmosfera" (MARQUES, 2015, p. 65).

São um elemento biológico essencial à vida humana (KLOCK \& CAMBI, 2010, p. 39), pois prestam à sociedade serviços ecossistêmicos que lhe garantem o bemestar necessário à sua sobrevivência.

A professora Ana Maria de Oliveira Nusdeo ao definir serviços ecossistêmicos também se refere a eles como serviços ambientais, considerando os termos sinônimos, pois ambos representam os "processos ecológicos que dão sustentação à vida" (NUSDEO, 2013, p. 12), que garantem a existência do meio ambiente necessário ao regular desenvolvimento do ser humano ${ }^{2}$.

De acordo com SOUZA (2015, p. 12), os serviços ecossistêmicos podem ser divididos em quatro categorias: serviços de provisão; serviços reguladores; serviços de suporte; e serviços culturais. 
Os bens da natureza fundamentais à sustentabilidade oferecem serviços de provisão quando, a partir do ecossistema, a sociedade obtém produtos essenciais à sua sobrevivência e subsistência, tais como alimentos, água, madeira, fibras, combustíveis, recursos genéticos, fármacos.

A regulação das condições ambientais é oferecida pelos serviços reguladores ao controlarem o clima, as enchentes, as doenças, garantindo a purificação da água, a polinização.

São serviços ecossistêmicos de suporte aqueles que produzem e mantém os demais serviços ambientais, como a ciclagem de nutrientes, o ciclo da água, a formação do solo, a produção primária.

Por fim, os serviços culturais representam benefícios imateriais obtidos pela sociedade a partir do ecossistema consistente em atividades espirituais, contemplativas, educacionais ou recreacionais, que geram também bem-estar ao ser humano.

Os serviços ambientais mantêm os ciclos vitais da natureza, os quais garantem a base natural para a sobrevivência das diferentes espécies (alimento, água, abrigo) (NUSDEO, 2013, p. 12).

As florestas, assim, são bens fundamentais à vida humana, pois, dentre os serviços ecossistêmicos, garantem a retenção de sedimentos, regulam as águas, alimentam as águas subterrâneas, são habitat para plantas e animais, regulam a temperatura e a precipitação, além de servirem como ambiente natural ao turismo e à recreação.

Prestam, pois, serviços de controle da erosão, de enchentes, de suprimento de água, de produção de alimentos, de madeira e de fibras, regulam o clima e permitem a polinização (SOUZA, 2015, p. 14), sendo ainda responsáveis pela captação do $\mathrm{CO}_{2}$ da atmosfera, controlando os efeitos da emissão de gases do efeito estufa ${ }^{3}$.

\section{USO ECONÔMICO DAS FLORESTAS}

O professor Luiz Marques relata que "[...] mais de 1 bilhão de pessoas vivem dentro dos 19 hotspots de biodiversidade florestal" (MARQUES, 2015, p. 65), sendo dependentes das florestas para sua sobrevivência como fonte direta de renda ou como rede de segurança econômica. 
O ICMS ecológico como forma de pagamento por serviços ambientais aos municípios paraenses para a redução do desmatamento amazônico

Relata, ainda, que "[...] cerca de 350 milhões das pessoas mais pobres do planeta, incluindo 60 milhões de indígenas, usam as florestas intensamente para sua subsistência e sobrevivência" (MARQUES, 2015, p. 65).

A interação do homem com as florestas indica que elas representam, além de provisão de serviços ecossistêmicos que garantem a sobrevivência da espécie humana, o sustentáculo econômico de parte da sociedade que direta e indiretamente delas retira sua subsistência ${ }^{4}$.

Contudo, no Brasil, o uso econômico das florestas (uso direto) representa uma tragédia para a humanidade, seja com relação a provisão de serviços ambientais, seja pela deterioração da possibilidade de exploração sustentável da floresta ${ }^{5}$.

O professor Virgílio Viana relata que “[...] desde o século XVI, quando cortamos o primeiro pau-brasil, até os dias de hoje, a história brasileira é marcada pelo uso predatório de nossas florestas" (VIANA, 2007, p. 23).

Em sua tese de doutorado, Gonzalo Enrique Vásquez Enríquez afirma que o uso da floresta na Amazônia não tem compromisso algum com planejamento de longo prazo (ENRÍQUEZ, 2008, p. 90), isto é, com o uso sustentável da natureza. Utilizam-se técnicas de desmatamento inadequadas, como o corte raso com motosserras, tratores com correntes, joga-se agente laranja e outros organocloretos sobre as árvores (MARQUES, 2015, p. 88), geram-se incêndios florestais, extrai-se predatoriamente a madeira, poluemse os rios e se realiza a pesca predatória.

De acordo com MARQUES (2015):

\begin{abstract}
Dados do IBGE-Prodes para o período 1970-2013 indicam uma perda da ordem de $22 \%$ da floresta amazônica, 763 mil km² ou, por amor de precisão, $762.979 \mathrm{~km}^{2}$. Detenhamo-nos um instante nesse número. Ele significa uma área equivalente a 184 milhões de campos de futebol, ou seja, duas Alemanhas $\left(375.051 \mathrm{~km}^{2}\right)$ e o triplo da área do estado de São Paulo $\left(248.222 \mathrm{~km}^{2}\right)$. Como mostra Antônio Donato Nobre, do Inpe e do Inpa: "É preciso se imaginar um trator com uma lâmina de 3 metros de comprimento, evoluindo a $756 \mathrm{~km} / \mathrm{h}$ durante quarenta anos sem interrupção: uma espécie de máquina de fim de mundo Segundo o conjunto das estimativas, isso representa 42 bilhões de árvores destruídas, isto é, duas mil árvores derrubadas por minuto ou 3 milhões por dia (...)”. (MARQUES, 2015, p. 81-82).
\end{abstract}

A partir da ótica de que os bens da natureza possuem também valor, o Brasil se empobrece, pois, a despeito dos ganhos com a produção agrícola ${ }^{6}$, não são calculados a perda da biodiversidade, as consequências do assoreamento dos rios, as mudanças climáticas. Cresce-se a economia, o PIB (produto interno bruto), mas se decresce em desenvolvimento ${ }^{7}-$ sustentável $^{8}$. 
O decréscimo em desenvolvimento sustentável - como não está vinculado unicamente à ideia de redução de receitas econômicas - representa o decréscimo de nível de qualidade da vida em todas as suas dimensões (ambiental, social, econômica, ética e jurídico-política $)^{9}$, causando preocupação a afirmação do professor Luiz Marques de que a floresta colapsa:

\begin{abstract}
As florestas, e não apenas a amazônica, aproximam-se do ponto crítico além do qual se desencadeiam retroalimentações positivas e, enfim, mudanças não lineares de estado que conduzem a seu declínio irreversível e à sua morte 'espontânea' (forest dieback). A partir de certo ponto, o impacto do desmatamento não é mais apenas local, mas repercute sistemicamente, alterando as condições climáticas, o ciclo hidrológico, a umidade do ar e do solo imprescindíveis para a sobrevivência do tecido florestal (MARQUES, 2015, p. 95-96).
\end{abstract}

Diante da possibilidade do colapso da floresta, inegável reconhecer que os serviços ecossistêmicos, muito mais do que o próprio resultado econômico do uso direto da floresta ${ }^{10}$, necessitam ser preservados, pois são base para a sobrevivência - existência ${ }^{11}$ - da espécie humana.

\title{
4. DEVER JURÍDICO DE PROTEÇÃo DA INTEGRIDADE DAS FLORESTAS E DOS SERVIÇOS ECOSSISTÊMICOS
}

A Constituição brasileira, no $\S 1^{\circ}$, do art. 225 , estabelece, em seus incisos, os deveres que competem ao Estado e à sociedade no que tange à preservação do meio ambiente ecologicamente equilibrado, que, no contexto deste artigo, pode ser entendido como o meio ambiente que fornece adequadamente bens e serviços necessários à existência da vida humana, os serviços ecossistêmicos.

Há, pois, dever jurídico constitucionalmente estabelecido de manutenção da integridade do fornecimento adequado de serviços ecossistêmicos a partir das florestas, sobretudo da floresta amazônica (SILVA, 2002, p. 89), objeto de especial proteção constitucional, juntamente com outros biomas nacionais. Qualquer atividade que cause alteração ou destruição da floresta, resultará prejuízo à sua função ecossistêmica e, por consequência, aos benefícios dela gerados à humanidade (SOUZA, 2015, p. 16-17).

A integridade da floresta é mandatória. Os meios de manutenção de sua integridade, contudo, são discricionários. 
O ICMS ecológico como forma de pagamento por serviços ambientais aos municípios paraenses para a redução do desmatamento amazônico

De acordo com Thomas \& Callan, “[...] pelo fato de ninguém ser o dono da atmosfera nem dos rios e córregos da Terra, não existe incentivo de mercado para impedir ou corrigir a contaminação desses recursos" (THOMAS \& CALLAN, 2014, p. 93).

Desse modo, o Estado pode lançar mão de políticas de comando e controle, regulamentando o uso dos bens da natureza, ou se utilizar de políticas de mercado, instituindo incentivos, econômicos ou tributários, ao seu uso de forma adequada preservando os serviços ambientais.

Representa política de comando e controle a instituição, por exemplo, de unidades de conservação ${ }^{12}$, sejam de proteção integral, em que se vedam quaisquer atividades humanas (uso direto) - o que implica em mantê-las intactas para que os processos ecossistêmicos não sejam alterados pela ação direta do homem - sejam de uso sustentável, em que a ação humana pode se dar de forma controlada, limitada e constantemente monitorada, a fim de que seu uso direto não altere significativamente os benefícios ecossistêmicos gerados.

Para Souza:

[...] as unidades de conservação representam remanescentes de ecossistemas naturais legalmente protegidos, possibilitando a perpetuidade de tais ambientes, de suas funções ecológicas e, consequentemente, dos seus serviços ecossistêmicos. Tais áreas possuem especial importância nas regiões altamente antropizadas e próximas de centros urbanos, onde geralmente representam os mais significativos, senão os únicos, remanescentes de ambientes naturais (SOUZA, 2015, p. 23).

O pagamento por serviços ambientais (PSA) representado por instrumentos, econômicos ou tributários, de pagamento direto ou indireto, pelo governo ou pelo cidadão, de valores àqueles que preservem os bens da natureza com a finalidade da manutenção dos serviços ecossistêmicos, encaixa-se como elemento da política de mercado.

Ana Maria Nusdeo conceitua o PSA como:

[...] transações entre duas ou mais partes envolvendo a remuneração àqueles que promovem a conservação, recomposição, incremento ou manejo de áreas de vegetação/ecossistema considerada apta a fornecer certos serviços ambientais, e ou que se abstém de práticas tendentes à sua degradação (NUSDEO, 2013, p. 13).

Nusdeo (2013) indica, ainda, que, para se considerar uma prática como PSA, um critério também deve ser observado - além do incentivo à manutenção dos serviços ecossistêmicos: o da adicionalidade. 
O critério da adicionalidade é analisado a partir da comprovação de um resultado positivo com relação aos serviços ambientais que só fora obtido em razão do pagamento com essa finalidade. Isto é, o pagamento pela proteção dos serviços ambientais não deve ocorrer se esta - proteção - ocorreria normalmente sem qualquer incentivo (business as usual).

O PSA cria um sistema de preços que incentiva os agentes a tomar decisões ambientalmente corretas (PEIXOTO, 2011, p. 17-18)

Portanto, o dever jurídico de proteção das florestas, a partir da discricionariedade da escolha dos meios de manutenção de sua integridade e de seus serviços ecossistêmicos gira em torno da utilização de políticas de comando e controle, mediante o uso controlado ou não-uso das florestas, ou de políticas de mercado, como o pagamento por serviços ambientais.

\section{O PAgAMENTO PELOS SERVIÇOS AMBIENTAIS FORNECIDOS PELAS FLORESTAS}

As políticas de comando e controle fazem parte do poder de império do Estado. O exercício de seu poder de polícia regula e limita o livre exercício dos direitos à liberdade e de propriedade do cidadão e do próprio Estado em favor do interesse público.

O não cumprimento das determinações desse tipo de política implica na aplicação de sanções ao inadimplente, seja pelo embargo de determinada atividade econômica, seja pela aplicação de multa.

As políticas de mercado, por sua vez, representam um estímulo ou desincentivo à prática predatória da natureza, não uma obrigação propriamente dita. Premia-se aquele que preserva os bens naturais e os benefícios dos serviços ambientais.

No caso da manutenção dos serviços ecossistêmicos da floresta amazônica, levando em conta a dificuldade de fiscalização do espaço rural amazônico, do reduzido gasto com estrutura dos órgãos que exercem o poder de polícia sobre essa área, bem como pela aplicação de penalidades baixas pelo desmatamento (ENRIQUEZ, 2008, p. 90), é natural se imaginar que o usuário da área tenderá a desmatá-la, desequilibrando, assim, a prestação de serviços ambientais essenciais à sobrevivência humana.

Raciocinando sobre as formas de proteção da floresta - amazônica -, Bertha Becker é enfática ao afirmar que "a floresta só deixará de ser destruída se tiver valor R. Fac. Dir. UFG, v. 41, n.2, p.87-109, maio / ago. 2017 
O ICMS ecológico como forma de pagamento por serviços ambientais aos municípios paraenses para a redução do desmatamento amazônico

econômico para competir com a madeira, com a pecuária e com a soja” (BECKER, 2005, p. 85).

A afirmação da geógrafa carioca deve ser avaliada a partir das estimativas apresentadas por MOTTA (2006, p. 55-56) de que o custo econômico do desmatamento na Amazônia é de US\$ 108,10 por hectare/ano ${ }^{13}$.

De acordo com MOTTA (2006, p. 12), o valor econômico dos recursos ambientais (VERA) é decomposto em valor de uso (VU) e valor de não-uso (VNU) e é representado pela seguinte equação:

\section{$\mathrm{VERA}=\mathrm{VU}+\mathrm{VNU}$}

Inseridos em VU (valor de uso), tem-se: a) Valor de uso direto (VUD), que representa o valor designado pela utilização direta do recurso natural, como a extração de minérios ou a visitação de áreas de interesse natural; b) Valor de uso indireto (VUI), que representa os valores que os indivíduos atribuem a um recurso ambiental quando são beneficiados pelas suas funções ecossistêmicas (contenção de erosão, reprodução de espécies, conservação de mangues); c) Valor de opção (VO), que representa o valor atribuído a um recurso ambiental em razão de seu não-uso no momento presente para ser usufruído no futuro, de forma direta ou indireta, como por exemplo a proteção de área de florestas tropicais para coleta futura de propriedades genéticas para serem utilizadas em terapias ou medicamentos.

O valor de não-uso (VNU) também é chamado de valor de existência (VE). Indica o valor atribuído pelo não-uso de um determinado recurso ambiental por razões morais, éticas, culturais ou altruísticas. A inclinação de um morador do estado do Mato Grosso pela proibição da caça de baleias na costa japonesa do oceano pacífico é um exemplo, pois este morador não obterá benefício direto qualquer em razão do não-uso e assim escolhe (pelo não-uso) em razão de valores não-econômicos, como a proteção da vida de animais não-humanos.

Os valores de uso direto (VUD) representam os benefícios privados locais (ao indivíduo que explora os recursos naturais), os valores de uso indireto (VUI) representam os benefícios públicos locais (à comunidade que indiretamente recebe os benefícios dos serviços ambientais) e os valores de opção (VO) e de existência (VE) representam os benefícios globais (à todos os sujeitos do planeta). 
Assim, a equação passa a ser representada da seguinte forma:

$$
\mathrm{VERA}=(\mathrm{VUD}+\mathrm{VUI}+\mathrm{VO})+\mathrm{VE}
$$

As estimativas apresentadas por MOTTA (2006) para alcançar o valor de US\$ 108,10 por hectare/ano como custo econômico do desmatamento são:

TABELA 1 - RESUMO DAS ESTIMATIVAS

\begin{tabular}{|c|c|c|c|c|}
\hline \multirow[b]{2}{*}{ Parcela de custo } & \multirow[b]{2}{*}{ US\$ por hectare/ano } & \multicolumn{3}{|c|}{ USS por hectare } \\
\hline & & $\begin{array}{c}\text { Taxa de desconto } \\
10 \% \text { a.a. }\end{array}$ & $\begin{array}{l}\text { Taxa de desconto } \\
6 \% \text { a.a. }\end{array}$ & $\begin{array}{l}\text { Taxa de desconto } \\
2 \% \text { a.a. }\end{array}$ \\
\hline Valor de uso direto & $\begin{array}{r}37,7 \\
(35 \%)\end{array}$ & 377 & 628,3 & 1.885 \\
\hline Produtos madeireiros & 28,5 & 285 & 475 & 1.425 \\
\hline Produtos não madeireiros & 0,2 & 2 & 3,3 & $\therefore \quad 10$ \\
\hline Ecoturismo & 9 & 90 & 150 & 450 \\
\hline Valor de uso indireto & $\begin{array}{l}18 \\
(17 \%)\end{array}$ & 180 & 300 & 900 \\
\hline Estocagem de carbono & 18 & 180 & 300 & 900 \\
\hline Valor de opçāo & $\begin{array}{l}21 \\
(19 \%)\end{array}$ & 210 & 350 & 1.050 \\
\hline Bioprospecção & 21 & 210 & 350 & 1.050 \\
\hline Valor de existência & $\begin{array}{l}31,2 \\
(31 \%)\end{array}$ & 312 & 520 & 15.600 \\
\hline Total & 108,1 & $1.081,0$ & $1.801,7$ & $19.445,0$ \\
\hline
\end{tabular}

Fonte: (MOTTA, 2006, p. 55).

Na composição do valor médio apresentado acima (custo econômico do desmatamento de US\$108,10 por hectare), MOTTA (2006) indica que: a) VUD = US\$ $37,70 /$ hectare $(35 \%) ; \mathrm{b})$ VUI $=$ US $\$ 18,00 /$ hectare $(17 \%) ; \mathrm{c})$ VO $=21,00 /$ hectare $(19 \%)$; d) $\mathrm{VE}=31,20 /$ hectare $(31 \%)$.

A partir desse resultado, MOTTA (2006) faz a seguinte análise:

Observa-se que os valores de uso direto, que seriam percebidos diretamente pela ótica da população local, seriam de US\$ 37,70 por hectare/ano ou $35 \%$ do valor total. Destes, apenas US\$28,70 por hectare/ano seriam de atividades extrativas.

(...) desde que o desmatamento seja financiado pela madeira extraída, a terra desmatada pode ser usada para pasto. Os valores de arrendamento de áreas de pastagem na região representariam, então, o quanto de renda o produtor local abriria mão pela simples cessão das suas terras para fins pecuários, uma vez removida a floresta e constituído o pasto.

Conforme mostra a tabela 4, esses valores de arrendamento para o ano de 2000 estariam variando entre US\$ 33,4 e US\$ 49,5 por hectare/ano, isto é, com valores sempre superiores aos estimados para os valores de uso direto de US\$ 
O ICMS ecológico como forma de pagamento por serviços ambientais aos municípios paraenses para a redução do desmatamento amazônico

28,7 a US\$ 37,7 por hectare/ano. Dessa forma, considerando as incertezas e os custos de transação de adoção de práticas de exploração florestal, as atividades sustentáveis aqui consideradas não seriam suficientes para criar um incentivo eficaz para que os produtores locais as adotassem" (MOTTA, 2006, p. 56-57).

O valor considerado por MOTTA (2006) para o arrendamento da área de pasto, a partir de sua própria metodologia, é dado pela tabela abaixo:

TABELA 2 - VALOR DO ARRENDAMENTO DA TERRA NA AMAZÔNIA LEGAL (1998-2001) - US\$ POR HECTARES/ANO

\begin{tabular}{|lccccccc|}
\hline $\begin{array}{l}\text { Arrendamentos de terras } \\
\text { para exploraçōes animais/ } \\
\text { estados da Amazônia Legal }\end{array}$ & Rondônia & Acre & Amazonas & Pará & Tocantins & Maranhão & Mato Grosso \\
\hline Jun. 1998 & 43,2 & - & 77,6 & 84,2 & 30,6 & 44,3 & 49,0 \\
Jun. 1999 & 31,1 & 50,8 & 50,6 & 37,6 & 28,3 & 33,8 & 30,8 \\
Jun. 2000 & 40,1 & 49,5 & - & 41,0 & 33,4 & 34,0 & 32,6 \\
\hline
\end{tabular}

Fonte: (MOTTA, 2006, p. 57).

A conclusão de MOTTA (2006) é a de que para aquele que usa diretamente o solo a partir do desmatamento (proprietário, detentor de domínio útil ou meramente possuidor), manter a floresta intacta não traz maiores benefícios (benefício privado local), uma vez que os valores de uso indireto (benefício público local), de opção e de existência (benefícios globais) representam ganhos difusos, não sujeitos à fruição individual.

Dentro do contexto apresentado por MOTTA (2006), se ocorresse o pagamento por serviços ambientais (valor de uso indireto - VUI), o usuário do solo receberia US\$ 18,00 por hectare/ano.

Desse modo, a garantia de integridade dos serviços ecossistêmicos pretendida que fosse levada à cabo - como solução de mercado - também pela sociedade, nos termos do caput, do art. 225, da Constituição, encontra-se frustrada pela lógica econômica.

O custo-benefício econômico da manutenção da floresta em pé apresentado por MOTTA (2006) ressoa como desincentivo ao usuário direto do solo à sua preservação.

Se as políticas de comando e controle, em razão da imensidão territorial e precariedade de meios tecnológicos na Amazônia, garantem apenas parcialmente a preservação da floresta e se o custo-benefício econômico da manutenção da Amazônia em pé não é convidativo ao usuário, algum meio precisa ser encontrado pelo Estado para manter os serviços ecossistêmicos da floresta. 


\section{DESMATAMENTO NA AMAZÔNIA E O ICMS ECOLÓGICO DO PARÁ COMO PSA}

Do ano de 1988 até o final do ano de 2015, o desmatamento na Amazônia Legal brasileira atingiu $413.506 \mathrm{~km}^{2}$ de sua área. Nesse contexto, o território do Estado do Pará possui $139.862 \mathrm{~km}^{2}$ de área desmatada, isto é, 33,82\% do desmatamento na Amazônia Legal se encontra em terras paraenses, de acordo com a tabela abaixo:

TABELA 3 - TAXAS ANUAIS DE DESMATAMENTO - 1988 ATÉ 2015 (KM²/ANO)

\begin{tabular}{|c|c|c|c|c|c|c|c|c|c|c|}
\hline AnolEstados & AC & AM & AP & MA & MT & PA & RO & RR & TO & $\begin{array}{c}\text { Amazônia } \\
\text { Legal }\end{array}$ \\
\hline $\mathbf{1 9 8 8}$ & 620 & 1510 & 60 & 2450 & 5140 & 6990 & 2340 & 290 & 1650 & 21050 \\
\hline $\mathbf{1 9 8 9}$ & 540 & 1180 & 130 & 1420 & 5960 & 5750 & 1430 & 630 & 730 & 17770 \\
\hline $\mathbf{1 9 9 0}$ & 550 & 520 & 250 & 1100 & 4020 & 4890 & 1670 & 150 & 580 & 13730 \\
\hline $\mathbf{1 9 9 1}$ & 380 & 980 & 410 & 670 & 2840 & 3780 & 1110 & 420 & 440 & 11030 \\
\hline $\mathbf{1 9 9 2}$ & 400 & 799 & 36 & 1135 & 4674 & 3787 & 2265 & 281 & 409 & 13786 \\
\hline $\mathbf{1 9 9 3}$ & 482 & 370 & - & 372 & 6220 & 4284 & 2595 & 240 & 333 & 14896 \\
\hline $\mathbf{1 9 9 4}$ & 482 & 370 & - & 372 & 6220 & 4284 & 2595 & 240 & 333 & 14896 \\
\hline $\mathbf{1 9 9 5}$ & 1208 & 2114 & 9 & 1745 & 10391 & 7845 & 4730 & 220 & 797 & 29059 \\
\hline $\mathbf{1 9 9 6}$ & 433 & 1023 & - & 1061 & 6543 & 6135 & 2432 & 214 & 320 & 18161 \\
\hline $\mathbf{1 9 9 7}$ & 358 & 589 & 18 & 409 & 5271 & 4139 & 1986 & 184 & 273 & 13227 \\
\hline $\mathbf{1 9 9 8}$ & 536 & 670 & 30 & 1012 & 6466 & 5829 & 2041 & 223 & 576 & 17383 \\
\hline $\mathbf{1 9 9 9}$ & 441 & 720 & - & 1230 & 6963 & 5111 & 2358 & 220 & 216 & 17259 \\
\hline $\mathbf{2 0 0 0}$ & 547 & 612 & - & 1065 & 6369 & 6671 & 2465 & 253 & 244 & 18226 \\
\hline $\mathbf{2 0 0 1}$ & 419 & 634 & 7 & 958 & 7703 & 5237 & 2673 & 345 & 189 & 18165 \\
\hline $\mathbf{2 0 0 2}$ & 883 & 885 & 0 & 1085 & 7892 & 7510 & 3099 & 84 & 212 & 21651 \\
\hline $\mathbf{2 0 0 3}$ & 1078 & 1558 & 25 & 993 & 10405 & 7145 & 3597 & 439 & 156 & 25396 \\
\hline $\mathbf{2 0 0 4}$ & 728 & 1232 & 46 & 755 & 11814 & 8870 & 3858 & 311 & 158 & 27772 \\
\hline $\mathbf{2 0 0 5}$ & 592 & 775 & 33 & 922 & 7145 & 5899 & 3244 & 133 & 271 & 19014 \\
\hline $\mathbf{2 0 0 6}$ & 398 & 788 & 30 & 674 & 4333 & 5659 & 2049 & 231 & 124 & 14286 \\
\hline $\mathbf{2 0 0 7}$ & 184 & 610 & 39 & 631 & 2678 & 5526 & 1611 & 309 & 63 & 11651 \\
\hline $\mathbf{2 0 0 8}$ & 254 & 604 & 100 & 1271 & 3258 & 5607 & 1136 & 574 & 107 & 12911 \\
\hline $\mathbf{2 0 0 9}$ & 167 & 405 & 70 & 828 & 1049 & 4281 & 482 & 121 & 61 & 7464 \\
\hline $\mathbf{2 0 1 0}$ & 259 & 595 & 53 & 712 & 871 & 3770 & 435 & 256 & 49 & 7000 \\
\hline $\mathbf{2 0 1 1}$ & 280 & 502 & 66 & 396 & 1120 & 3008 & 865 & 141 & 40 & 6418 \\
\hline $\mathbf{2 0 1 2}$ & 305 & 523 & 27 & 269 & 757 & 1741 & 773 & 124 & 52 & 4571 \\
\hline $\mathbf{2 0 1 3}$ & 221 & 583 & 23 & 403 & 1139 & 2346 & 932 & 170 & 74 & 5891 \\
\hline $\mathbf{2 0 1 4}$ & 309 & 500 & 31 & 257 & 1075 & 1887 & 684 & 219 & 50 & 5012 \\
\hline $\mathbf{2 0 1 5}$ & 279 & 769 & 13 & 217 & 1508 & 1881 & 963 & 148 & 53 & 5831 \\
\hline $\mathbf{A c u m u l a d o}$ & & & & & & & & & & \\
$\mathbf{1 9 8 8 - 2 0 1 5}$ & 13333 & 22420 & 1506 & 24412 & 139824 & 13986256418 & 7170 & 8560 & 413506 \\
\hline & PRODE & P95 & \\
\hline
\end{tabular}

Fonte: PRODES Projeto de Estimativa do Desflorestamento da Amazônia - INPE

De acordo com a Tabela 3 (acima) e com o Gráfico 1 (abaixo), a área de avanço do desmatamento no Estado do Pará reduziu-se bastante após o ano de 2004, 
O ICMS ecológico como forma de pagamento por serviços ambientais aos municípios paraenses para a redução do desmatamento amazônico

quando atingiu o equivalente a $8870 \mathrm{~km}^{2}$ de desmatamento, tendo-se desmatado $1881 \mathrm{~km}^{2}$ no ano de 2015.

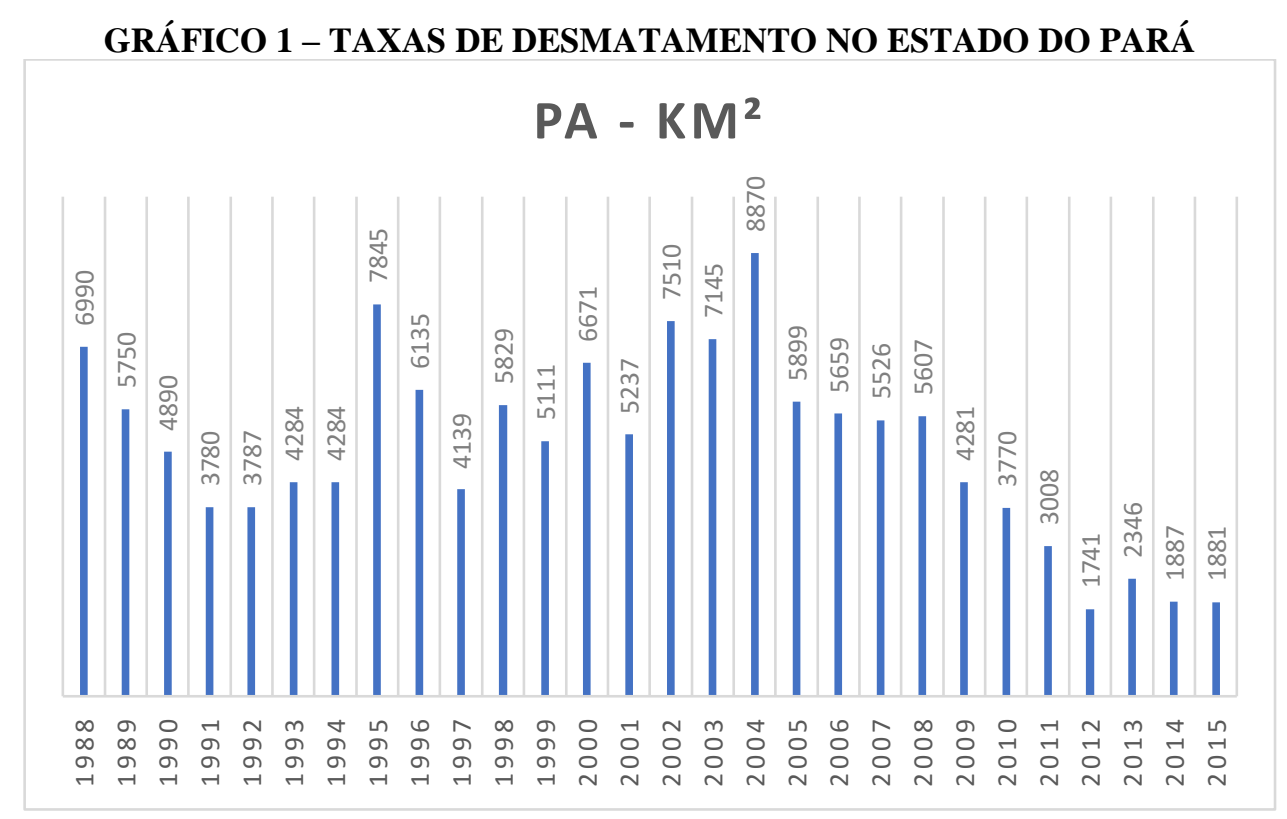

Fonte: elaboração dos autores

O combate ao avanço do desmatamento na Amazônia Legal, a partir do mencionado ano de 2004, é realizado por diversas políticas de comando e controle do governo federal inseridas no Plano de Ação de Prevenção e Controle do Desmatamento na Amazônia (PPCDAM), lançado em abril de 2004, que tem como eixos de atuação: 1) o ordenamento fundiário e territorial, 2) o monitoramento e controle ambiental e 3) o fomento de atividades produtivas sustentáveis.

De acordo com Silva:

O Plano abarca, desde o ano 2004, o ordenamento territorial e fundiário, monitoramento, fiscalização e controle ambiental, e fomento às atividades produtivas sustentáveis, mobilizando diversos órgãos dos ministérios, em parceria com os governos estaduais, prefeituras, entidades da sociedade civil e do setor privado. Os recursos deste plano advêm dos orçamentos próprios dos órgãos envolvidos e também do "Fundo Amazônia", gerido pelo Banco Nacional de Desenvolvimento Econômico e Social (BNDES) (SILVA, 2014, p. 22).

Com a finalidade de auxiliar o combate ao desmatamento ilegal na Amazônia paraense, o Estado do Pará lançou, em 2009, seu Plano de Prevenção, Controle e Alternativas ao Desmatamento (PPCAD), que se alinha aos objetivos do PPCDAM do governo federal. 
No bojo do PPCAD estava inserido como meta a ser atingida até o ano de 2012 aprovar, regulamentar e implementar o ICMS Ecológico como instrumento de política fiscal pró-sustentabilidade.

O ICMS Ecológico proposto, na lição dos professores Fernando Scaff e Lise Tupiassu, representa "um forte instrumento econômico extrafiscal com vistas à consecução de uma finalidade constitucional de preservação" (SCAFF \& TUPIASSU, 2004, p. 172).

Desse modo, surge o ICMS Ecológico no Estado do Pará como um instrumento econômico-financeiro de garantia da sustentabilidade no contexto das políticas públicas de redução do desmatamento na Amazônia.

\subsection{Implantação do ICMS ecológico no estado do Pará}

O ICMS Ecológico representa uma forma de divisão das receitas do imposto sobre circulação de mercadorias e prestações de serviços de transporte intermunicipal, interestadual e de comunicações (ICMS) - de competência tributária do Estado - aos municípios do Estado a partir de um critério adjetivado de ecológico.

A participação dos municípios na receita do ICMS (repita-se, imposto de competência estadual), decorre do disposto no art. 158, da Constituição federal.

Esse dispositivo determina que os valores decorrentes da arrecadação do ICMS sejam repartidos com os municípios na seguinte proporção: 75\% da arrecadação pertence ao Estado e os demais $25 \%$ pertence a todos municípios (inciso IV). É obrigação do Estado, portanto, entregar, sem retenções ${ }^{14}$, aos municípios, $25 \%$ de sua receita de ICMS.

Assim, considerados os 25\% da receita de ICMS de direito dos municípios, há uma nova divisão da receita, conforme os critérios constitucionais (inciso I e II, do parágrafo único, do art. 158, da Constituição federal): a) 3/4, no mínimo, deve ser repartido aos municípios de acordo com o valor adicionado nas operações e prestações relativas ao ICMS ocorridas em seus territórios (Valor Adicionado Fiscal - VAF); b) 1/4, no máximo, de acordo com os critérios definidos livremente pela legislação estadual.

De acordo com a lei estadual paraense n. 5.645/91, que regula o mencionado dispositivo da Constituição Federal, os 3/4 da parcela municipal de ICMS repartida em razão do critério do Valor Adicionado Fiscal (VAF) dependem unicamente da capacidade do município beneficiário de servir de suporte territorial para a prática dos fatos geradores 
O ICMS ecológico como forma de pagamento por serviços ambientais aos municípios paraenses para a redução do desmatamento amazônico

do ICMS, isto é, que haja, por exemplo, comércio de mercadorias ou transporte de pessoas ou cargas a partir de seus territórios.

A definição dos critérios de repartição do restante dos $25 \%$ da receita do ICMS pertencentes aos municípios também veio regulada, no Pará, pela lei estadual n. $5.645 / 91$.

Até o ano de 2012, a mencionada lei estabelecia que a divisão entre os municípios dos 1/4 (25\%) do ICMS se desse a partir dos seguintes critérios: cinco por cento $(5 \%)$ na proporção da população do seu território; cinco por cento $(5 \%)$ na proporção da superfície territorial; quinze por cento (15\%) distribuídos igualmente entre todos os municípios.

A partir da alteração realizada pela lei estadual n. 7.638, de 12 de julho de 2012, foi inserido o critério ecológico ${ }^{15}$ para o recebimento da cota-parte do ICMS.

O critério ecológico, de acordo com o art. $2^{\circ}$ da lei estadual n. 7.638/12 ${ }^{16}$, exige que o município abrigue em "seu território unidades de conservação e outras áreas protegidas" (BRASIL, 2012).

Assim, já levando em consideração o critério ecológico, os $25 \%$ de repartição da receita do ICMS passa a ocorrer do seguinte modo $^{17}$ : sete por cento (7\%) distribuídos igualmente entre todos os municípios; cinco por cento (5\%) na proporção da população do seu território; cinco por cento $(5 \%)$ na proporção da superfície territorial; oito por cento $(8 \%)$ de acordo com o critério ecológico ${ }^{18}$.

Como requisitos para o recebimento do ICMS Ecológico, a lei estadual definiu que os municípios devem organizar e manter seu próprio Sistema Municipal do Meio Ambiente, composto, no mínimo, por: Conselho Municipal do Meio Ambiente, de caráter deliberativo e composição socialmente paritária; Fundo Municipal do Meio Ambiente; Órgão público administrativo executor da Política Municipal do Meio Ambiente, dotado de recursos humanos, materiais e financeiros adequados e suficientes para exercer suas funções, em especial, a implantação do processo de planejamento e o Plano Municipal do Meio Ambiente, visando consolidar a Agenda 21 Local; Demais instrumentos de política pública e participativa necessários à plena execução da Política Municipal do Meio Ambiente.

Os recursos recebidos a partir do critério ecológico devem ser destinados preferencialmente à operacionalização de um Fundo Municipal do Meio Ambiente, a ser gerido pelo Conselho Municipal de Meio Ambiente. 
A inserção do critério ecológico representa a regulamentação do $\S 2^{\circ}$, do art. 225, da Constituição estadual, que dispõe:

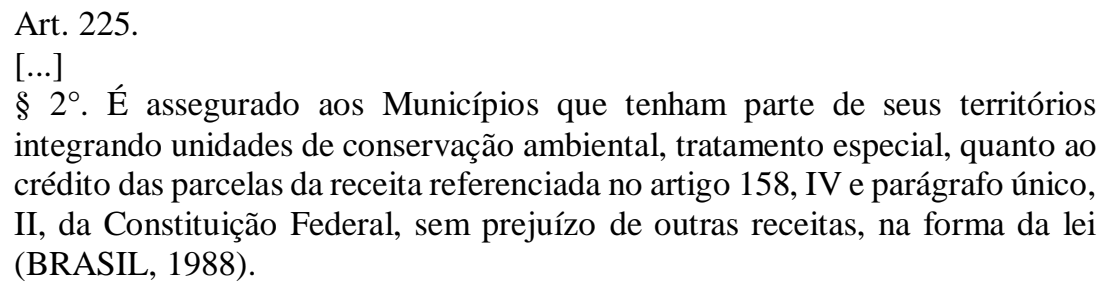
integrando unidades de conservação ambiental, tratamento especial, quanto ao crédito das parcelas da receita referenciada no artigo 158, IV e parágrafo único, II, da Constituição Federal, sem prejuízo de outras receitas, na forma da lei (BRASIL, 1988).

A Constituição do Estado do Pará foi promulgada em 05 de outubro de 1989 e, nesta data, já constava o $\$ 2^{\circ}$, do art. 225, com a redação atual. Levou-se quase 23 (vinte e três) anos para que o tratamento especial definido fosse regulamentado pela Lei estadual n. $7.638 / 12$.

\subsection{Critérios de repasse do ICMS ecológico no Pará como proteção dos serviços ecossistêmicos da floresta}

O Decreto estadual n. 775, de 26 de junho de 2013, regulamentando a lei estadual n. 7.638/12, definiu que o repasse aos municípios da porcentagem equivalente ao critério ecológico (ICMS Verde ${ }^{19}$ ) se dará de acordo com os seguintes critérios e indicadores: $25 \%$ do valor total do repasse com base na porcentagem do território municipal ocupado por unidades de conservação de proteção integral e de uso sustentável (em nível federal, estadual e municipal), terras indígenas, terras quilombolas e áreas militares; $25 \%$ do valor total do repasse com base na existência de estoque mínimo de cobertura vegetal nativa original e na redução do desmatamento no território do município calculado a partir dos dados fornecidos pelo Instituto Nacional de Pesquisas Espaciais INPE; $50 \%$ do valor total do repasse considerando a área cadastrável do município inserida no Cadastro Ambiental Rural ${ }^{20}$.

O primeiro indicador corresponde, portanto, aas unidades de conservação ${ }^{21}$, que correspondem a áreas com limitação total (proteção integral) ou parcial (uso sustentável) do uso do território de floresta, garantindo que a manta florestal permaneça produzindo os benefícios dos serviços ecossistêmicos.

Tupiassu \& Oliveira em recente artigo observam que as "Unidades de Proteção Integral, Terras Indígenas e Áreas Militares em geral implicam em um grau de 
O ICMS ecológico como forma de pagamento por serviços ambientais aos municípios paraenses para a redução do desmatamento amazônico

restrição de uso bastante superior àquele aplicado às Unidades de Uso Sustentável e Terras Quilombolas” (TUPIASSU; OLIVEIRA, 2016, p. 290).

Quanto menor o uso do território da floresta ou seu uso de forma sustentável, maior será a preservação dos serviços ambientais a serem fornecidos pela hiléia amazônica $^{22}$.

O segundo indicador divide-se em dois elementos: i) existência de cobertura vegetal nativa original mínima e ii) redução do desmatamento medido pelo INPE. São subcritérios que estão profundamente ligados à manutenção das condições básicas ao fornecimento de serviços ecossistêmicos pela floresta.

Em primeiro lugar, requer-se a existência de um mínimo (20\%) de floresta nativa original, indicando a necessidade para o recebimento do ICMS Ecológico de que o território do município não seja totalmente desmatado ${ }^{23}$, o que implicaria na prestação nula de serviços ambientais florestais.

Em segundo lugar, exigir-se a redução do desmatamento permite a manutenção da floresta em pé, o que é essencial para que não haja a substituição da floresta tropical por savana (FEARNSIDE, 2011, p. 228), o que impossibilita a fruição dos serviços ecossistêmicos.

O terceiro critério é definido pelo cadastramento das áreas do município no Cadastro Ambiental Rural (CAR), consistindo em uma das formas pelas quais torna-se possível monitorar o uso adequado do espaço da floresta, uma vez que os dados das propriedades tornam-se mais facilmente conhecidos do Poder Público que, diante da informações, dispõe de melhores elementos para tomada de decisões, dentre elas da escolhas dos modos de controle do desmatamento ${ }^{24}$.

Veja-se que os critérios de repartição do ICMS Ecológico inclinam essa política pública ao controle e à redução do desmatamento da floresta amazônica no território municipal.

O recebimento de parcela maior do repasse do ICMS em razão do controle do desmatamento indica que os municípios estão recebendo um incentivo para auxiliar o Estado nesse objetivo.

Se os municípios cumprirem os requisitos estabelecidos pelo Decreto estadual n. 775/13 e pela lei estadual n. 7.638/12, têm a possibilidade de receber maiores repasses do ICMS (inseridos nos $8 \%$ de repasse em função do critério ecológico). 
A proteção dos serviços ecossistêmicos a partir do cumprimento dos critérios ecológicos representa a adicionalidade mencionada por Nusdeo (2013). Os municípios implantam ou gerenciam de forma adequada as áreas protegidas e de uso especial, mantêm cobertura vegetal nativa mínima, reduzem as taxas de desmatamento e inscrevem suas áreas no CAR em razão da pretensão de recebimento maiores parcelas do ICMS Ecológico.

Não houvesse esse incentivo, não há garantias de que políticas de comando e controle alcançariam os mesmos objetivos. Há adicionalidade para que se receba o ICMS Ecológico.

Considerando que a redução do desmatamento implica na proteção da geração de benefícios à sociedade decorrentes dos serviços ambientais da floresta amazônica, o ICMS Ecológico representa um pagamento por serviços ecossistêmicos ${ }^{25}$, na esteira do que já vem sendo estudado por VEIGA NETO (2008).

A partir da configuração da política voltada para a valorização da floresta em pé, os municípios passam a ter um incentivo para a preservação do status original do bioma amazônico, propiciando-se, assim, uma intervenção não coercitiva na formulação das ações voltadas à preservação dos serviços ecossistêmicos.

\section{CONSIDERAÇÕES FINAIS}

A definição do pagamento por serviços ecossistêmicos está condicionada a existência de duas contingências: a proteção dos benefícios gerados pelos bens da natureza (serviços ambientais) e atuação do protetor condicionada ao recebimento do pagamento (adicionalidade).

Todas as políticas públicas que estabelecerem uma remuneração, direta ou indireta, econômica ou tributária, para que um determinado sujeito comporte-se de forma a proteger os serviços ecossistêmicos gerados a partir do espaço em que ocupa, poderão ser classificadas como formas de pagamento por serviços ambientais (PSA).

O ICMS Ecológico do Estado do Pará conforma o recebimento da repartição constitucional da receita do ICMS aos municípios a partir do critério ecológico, que significa a necessidade de cumprimento de objetivos com a finalidade de proteção da floresta amazônica localizada em seu território (gestão adequada de áreas de proteção e de uso especial, manutenção de cobertura vegetal nativa original mínima, redução do desmatamento e inscrição no cadastro ambiental rural). 
O ICMS ecológico como forma de pagamento por serviços ambientais aos municípios paraenses para a redução do desmatamento amazônico

Se os objetivos ecológicos forem alcançados, o município obterá maior quantidade de recursos decorrente da repartição do ICMS. Se, por outro lado, os objetivos não se concretizarem, o município deixa de receber uma parcela que só seria sua por direito próprio se o critério ecológico tivesse sido preenchido.

O ICMS Ecológico, assim, enquadra-se como modalidade de pagamento por serviços ambientais, uma vez que está relacionado a entrega de benefícios econômicos ou tributários àquele que garantir a proteção de serviços ecossistêmicos - neste caso, decorrentes da floresta amazônica - que não decorre do business as usual.

\section{REFERÊNCIAS}

BECKER, Bertha K. Geopolítica da Amazônia. Estudos Avançados, São Paulo, v. 19, n. 53, p. 71-86, 2005.

ENRÍQUEZ, Gonzalo Enrique Vásquez. Desafios da sustentabilidade da Amazônia: biodiversidade, cadeiras produtivas e comunidades extrativistas integradas. Tese (Doutorado em Desenvolvimento Sustentado). Universidade de Brasília, Brasília, 2008.

FEARNSIDE, Philip. Floresta amazônica e clima. In: NUSSENZVEIG, Herch Moysés (org.). O futuro da terra. Rio de Janeiro: FGV, 2011.

FREITAS, Juarez. Sustentabilidade: Direito ao Futuro. $2^{\text {a }}$. Ed. Belo Horizonte: Ed. Fórum, 2012.

GUIMARÃES, Roberto P.; BEZERRA, Joana. Novas Questões ou velhos problemas: a posição do Brasil na agenda internacional do meio ambiente. In: FERREIRA, Leila da Costa (org.). A questão ambiental na América Latina: teoria social e interdisciplinaridade. Campinas: Unicamp, 2011.

INSTITUTO DE DESENVOLVIMENTO ECONÔMICO, SOCIAL E AMBIENTAL DO PARÁ. Contribuições ao debate na aplicação do ICMS Verde no Estado do Pará. Belém: IDESP, 2013.

KLOCK, Andréa Bulgakov; CAMBI, Eduardo. Vulnerabilidade Socioambiental. In: DIAS, Jean Carlos; FONSECA, Luciana Costa da. (orgs.). Sustentabilidade: ensaios sobre Direito Ambiental. São Paulo: Método, 2010.

MARQUES, Luiz. Capitalismo e colapso ambiental. Campinas: Unicamp, 2015.

MOTTA, Ronaldo Seroa da. Economia ambiental. Rio de Janeiro: FGV, 2006.

NUSDEO, Ana Maria de Oliveira. Pagamento por serviços ambientais. Do debate de política ambiental à implementação jurídica. In: LAVRATTI, Paula; TEJEIRO, Guillermo (orgs.). Direito e mudanças climáticas: Pagamentos por Serviços 
Ambientais, fundamentos e principais aspectos jurídicos. São Paulo: Instituto $O$ Direito por um Planeta Verde, 2013.

OLIVEIRA, Adriano Carvalho. ICMS Ecológico e desenvolvimento: análise dos estados de Rondônia, Tocantins, Ceará e Pará. Dissertação (Mestrado em Direito). Centro Universitário do Estado do Pará, Belém, 2014.

PARÁ. Programa de Prevenção, Controle e Alternativas ao Desmatamento do Estado do Pará. 2009. Disponível em: <http://www.sema.pa.gov.br/download /PPCAD_versao_consultas_11_05_SITESEMA.pdf> Acesso em: 7 jan. 2013.

PEIXOTO, Marcus. Pagamento por serviços ambientais: aspectos teóricos e proposições legislativas. Brasília: SENADO, 2011. (Texto para discussão n. 105).

SACHS, Ignacy. Caminhos para o desenvolvimento sustentável. $4^{\text {a }}$. Ed. Rio de Janeiro: Garamond, 2002.

SANTOS, Daniel; PEREIRA, Denys; VERÍSSIMO, Adalberto. O estado da Amazônia: uso da terra. Belém: Imazon, 2013.

SCAFF, Fernando Facury; TUPIASSU, Lise Viera da Costa. Tributação e políticas públicas: o ICMS ecológico. Verba Juris. João Pessoa. ano 3, n. 3, jan./dez. 2004.

SILVA, José Afonso. Direito Ambiental Constitucional. $4^{\text {a }}$ ed. São Paulo: Malheiros, 2002 .

SOUZA, Luiz Fernando de. Serviços Ecossistêmicos. In: STANTON, Márcia Silva (org.). Manual de Apoio à atuação do Ministério Público: pagamento por serviços ambientais. Porto Alegre: Andrefc.com Assessoria e Consultoria em Projetos, 2015.

THOMAS, Janet M.; CALLAN, Scott J. Economia Ambiental: fundamentos, políticas e aplicações. São Paulo: Cengage Learning, 2014.

TUPIASSU, Lise Vieira da Costa; OLIVEIRA, Adriano Carvalho. ICMS Verde para a redução do desmatamento amazônico: estudo sobre uma experiência recente. Veredas do Direito, Belo Horizonte, v.13, n.25, p.277-306, Janeiro/abril de 2016.

VEIGA NETO, Fernando Cesar da. A construção dos mercados de serviços ambientais e suas implicações para o desenvolvimento sustentável no Brasil. 2008. $286 \mathrm{f}$. Tese (Doutorado em Desenvolvimento, Agricultura e Sociedade) - Instituto de Ciências Humanas e Sociais, Universidade Federal Rural do Rio de Janeiro, Rio de Janeiro, 2008.

VEIGA, José Eli da. Desenvolvimento sustentável: o desafio do século XXI. Rio de Janeiro: Garamond, 2010.

VIANA, Virgílio. As florestas e o desenvolvimento sustentável na Amazônia. 2a . Ed. Manaus: Editora Valer, 2007. 
O ICMS ecológico como forma de pagamento por serviços ambientais aos municípios paraenses para a redução do desmatamento amazônico

Artigo recebido 09 de agosto de 2016 e aceito em 25 de novembro de 2017

\begin{abstract}
${ }^{1}$ De acordo com Edson Ferreira de Carvalho (apud KLOCK \& CAMBI, 2010, p. 44), os bens naturais são fundamentais porque o "homem não pode sobreviver mais do que quatro minutos sem respirar, mais do que uma semana sem beber água e mais de que um mês sem se alimentar", sendo a Terra o único local conhecido no universo em que o homem pode respirar, tomar água e se alimentar.
\end{abstract}

${ }^{2}$ Neste artigo serão adotados, ambos os termos, como sinônimos.

3 "Outra grande preocupação é a possibilidade de extensas liberações de carbono do solo, na Amazônia e no resto do mundo. O aquecimento global deve alterar o equilíbrio entre formação e oxidação de matéria orgânica, levando muito do carbono armazenado a escapar. Isso é muito grave, porque há um grande estoque de carbono no solo da Amazônia. Isto pode contribuir para um possível "efeito estufa incontrolável" (runaway greenhouse effect). Estamos liberando, hoje, por volta de 10 bilhões de toneladas de carbono anualmente por ação humana. São uns 8 bilhões com combustíveis fósseis e cimento, mais uns 2 bilhões com desmatamento. Então, a não ser que se invente uma nova tecnologia para depositar e ter carbono sob o solo, o máximo que podemos fazer é parar completamente as emissões, não queimar mais nenhum combustível fóssil, parar totalmente o desmatamento e, com isso, diminuir as emissões em 10 bilhões de toneladas. Mas se continuassem assim mesmo, sendo liberados mais de 10 bilhões de toneladas de carbono do solo devido ao aquecimento global, isso reforçaria ainda mais o aquecimento e a liberação (realimentação positiva) e acabaria fugindo de nosso controle, produzindo uma catástrofe maior. O desmatamento também esquenta o solo e libera muito carbono, outra razão para manter a floresta onde está.

${ }^{4}$ As mantas vegetais nativas do planeta - florestas, mangues etc - são comunidades vivas nas quais interagem árvores e demais vegetas, animais, fungos, bactérias e micro-organismos em geral. A espécie humana faz parte dessas comunidades" (MARQUES, 2015, p. 65).

5 “(...) poucas pessoas têm noção certa do que representa a destruição da floresta. E é limitada a capacidade de entender suas implicações, já que poucos também sabem ao certo os reais impactos do desmatamento da Amazônia sobre os climas regionais ou ainda sobre o aquecimento global. É pouco provável entender ou prever hoje os efeitos da perda de organismos que melhoram nossa qualidade de vida. Mas, sabe-se que o processo evolutivo da floresta nunca se repetirá. Sua destruição, fazenda por fazenda, e cada um dos projetos hidrelétricos em operação, causa tantas mudanças climáticas, e com tanta rapidez, tanto em escalas microscópicas como globais, que não podemos acompanhar seus efeitos" (ENRÍQUEZ, 2008, p. 90).

${ }^{6}$ A extração ilegal de madeira é um dos negócios mais florescentes do mundo (MARQUES, 2015, p. 89).

${ }^{7}$ Ninguém duvida de que o crescimento é um fator muito importante para o desenvolvimento. Mas não se deve esquecer que o no crescimento a mudança é quantitativa, enquanto no desenvolvimento ela é qualitativa. Os dois estão intimamente ligados, mas não são a mesma coisa. 
E sob vários prismas a expansão econômica chega a ser bem mais intrigante que o desenvolvimento" (VEIGA, 2010, p. 56)

8 "O desenvolvimento sustentável é, evidentemente, incompatível com o jogo sem restrições das forças do mercado (SACHS, 2002, p. 55)

${ }^{9}$ Para consolidar o bem-estar é indispensável "cuidar do ambiental, sem ofender o social, o econômico, o ético e o jurídico-político" (FREITAS, 2012, p. 57). O "ambiental”, o " social”, o "econômico", o "ético" e o "jurídico-político" são as dimensões da vida que, para o professor Juarez Freitas, "se entrelaçam e se constituem mutuamente, numa dialética da sustentabilidade" (FREITAS, 2012, p. 71)

${ }^{10}$ Nossa participação no mercado internacional de madeiras tropicais é pequena, mas aumenta a cada ano: saltou de 2,5\% em 1990 para 8\% em 1995 e 29,3\% em 2003 (ITTO, 2003). Infelizmente, a maior parte da produção vem de áreas de desmatamento e de extração predatória de madeira" (VIANA, 2007, p. 27).

11 “(...) poderíamos afirmar que a humanidade vivencia nos dias de hoje a exaustão de um estilo de desenvolvimento ecologicamente suicida (pois acaba com a base de recursos naturais), socialmente perverso (gera pobreza e desigualdade), politicamente injusto (dificulta o acesso aos recursos), eticamente censurável (desrespeita formas de vida não humanas) e culturalmente alienado (subjuga a natureza)" (GUIMARÃES \& BEZERRA, 2011, p. 86).

${ }^{12}$ Unidade de conservação é o "espaço territorial e seus recursos ambientais, incluindo as águas jurisdicionais, com características naturais relevantes, legalmente instituído pelo Poder Público, com objetivos de conservação e limites definidos, sob regime especial de administração, ao qual se aplicam garantias adequadas de proteção (lei 9.985/00, art. $2^{\circ}$, inciso I).

${ }^{13}$ Valor apurado para o ano de 2000 e de acordo com metodologia própria utilizada pelo autor (MOTTA, 2006, p. 41)

${ }^{14}$ STF - RE 572762, Relator(a): Min. RICARDO LEWANDOWSKI, Tribunal Pleno, julgado em 18/06/2008, DJe-167 05-09-2008.

15 Através da implementação do ICMS Ecológico opera-se uma nova lógica de distribuição da receita de ICMS aos municípios, que passam a ser recompensados pela adequação de seu território aos critérios escolhidos pela política pública (OLVEIRA, 2014, p. 81).

$16 \mathrm{O}$ art. 2o. exige também que os municípios participem da implementação e da gestão das unidades de conservação e áreas protegidas existentes em seus territórios

${ }^{17}$ De acordo com o art. $3^{\circ}$, da Lei estadual n. 5.645/91, alterado pelo art. $8^{\circ}$, da lei estadual n. $7.638 / 12$

${ }^{18} \mathrm{O}$ art. 9o., da lei estadual n. 7.638/12, determina que o critério ecológico seja aplicado de forma sucessiva, anual e progressiva nos anos de 2012 (2\%), 2013 (4\%) e 2014 (6\%). De 2015 em diante $8 \%$. Esta forma de aplicação se deu com a finalidade de mitigar os impactos da redução da receita distribuída aos municípios com base no critério da igualdade.

${ }^{19}$ Art. $2^{\circ}$ A parcela de ICMS distribuída segundo o critério ecológico será designada "ICMS Verde", para os fins da política fiscal e de meio ambiente do Estado do Pará (Decreto estadual n. $775 / 2013)$.

${ }^{20}$ CAR: Cadastro Ambiental Rural, criado pela lei ${ }^{\circ}$ 12.651, de 25 de maio de 2012, é um instrumento de auxílio no processo de regularização ambiental de propriedades e posses rurais. R. Fac. Dir. UFG, v. 41, n.2, p.87-109, maio / ago. 2017

ISSN 0101-7187 
O ICMS ecológico como forma de pagamento por serviços ambientais aos municípios paraenses para a redução do desmatamento amazônico

Consiste no levantamento de informações georreferenciadas do imóvel, com delimitação das Áreas de Proteção Permanente (APP), Reserva Legal (RL), remanescentes de vegetação nativa, área rural consolidada, áreas de interesse social e de utilidade pública, com o objetivo de traçar um mapa digital a partir do qual são calculados os valores das áreas para diagnóstico ambiental (http://www.mma.gov.br/desenvolvimento-rural/cadastro-ambiental-rural).

${ }^{21}$ As unidades de conservação são definidas pela Lei n. 9.985/00, como "espaço territorial e seus recursos ambientais, incluindo as águas jurisdicionais, com características naturais relevantes, legalmente instituído pelo Poder Público, com objetivos de conservação e limites definidos, sob regime especial de administração, ao qual se aplicam garantias adequadas de proteção" (art. $2^{\circ}$, inciso I)

22 "Os usos e não usos dos recursos ambientais encerram valores que precisam ser mensurados para se fazerem opções entre usos e não usos diversos e até mesmo conflitantes, ou seja, quando um tipo de uso ou de não uso exclui, necessariamente, outro tipo de uso ou não uso. Por exemplo, o uso da baía de Guanabara para diliuição de esgoto exclui (ou pelo menos limita) seu uso para recreação" (MOTTA, 2006, p. 12).

${ }^{23}$ Interessante observar a complementariedade entre os dois elementos que compõem o inciso II do art. $4^{\circ}$ do Decreto paraense . $^{\circ} 775 / 2013$, na medida em que determina uma meta de redução de desmatamento, exigindo, ao mesmo tempo, uma taxa mínima de cobertura vegetal. Isso porque, muitas vezes, verifica-se uma redução de taxas de desmatamento em determinado local simplesmente porque a cobertura vegetal já foi toda destruída, não havendo mais nada o que desmatar. Nesse caso, a redução do desmatamento falseia a realidade" (TUPIASSU \& OLIVEIRA, 2016, p. 294).

24 Ao inserir dois outros critérios, a lei do ICMS Verde apresentou-se mais abrangente, beneficiando, também, os municípios que ainda dispõem de uma área mínima de 1. remanescente florestal; 2. diminuição das taxas de desmatamento e 3. realização do Cadastro Ambiental Rural. Dessa maneira, todos os municípios passam a ser beneficiários com base na soma desses critérios e tendo seu valor de repasse de ICMS Verde igualmente proporcional” (IDESP, 2013, p. 16).

25 Contudo, o pagamento não se realiza aos usuários diretos do solo (proprietários, detentores de domínio útil ou meros possuidores), mas sim aos municípios como agentes com a missão de garantir a preservação da floresta mediante a redução do desmatamento 